Ferrata Storti Foundation

\title{
Prevention of the anti-factor VIII memory B-cell response by inhibition of Bruton tyrosine kinase in experimental hemophilia A
}

Haematologica 2019

Volume 104(5):1046-1054

\section{Correspondence:}

SÉBASTIEN LACROIX-DESMAZES

sebastien.lacroix-desmazes@crc.jussieu.fr

Received: June 21, 2018.

Accepted: November 22, 2018.

Pre-published: December 13, 2018.

doi:10.3324/haematol.2018.200279

Check the online version for the most updated information on this article, online supplements, and information on authorship \& disclosures: www. haematologica.org/content/104/5/1046

\section{(C)2019 Ferrata Storti Foundation}

Material published in Haematologica is covered by copyright. All rights are reserved to the Ferrata Storti Foundation. Use of published material is allowed under the following terms and conditions:

https://creativecommons.org/licenses/by-nc/4.0/legalcode. Copies of published material are allowed for personal or internal use. Sharing published material for non-commercial purposes is subject to the following conditions:

https://creativecommons.org/licenses/by-nc/4.0/legalcode, sect. 3. Reproducing and sharing published material for commercial purposes is not allowed without permission in writing from the publisher.

\author{
Sandrine Delignat, ${ }^{1,2,3}$ Jules Russick, ${ }^{1,2,3}$ Bagirath Gangadharan, ${ }^{1,2,3}$ Julie \\ Rayes, ${ }^{1,2,3}$ Mathieu Ing, ${ }^{1,2,3}$ Jan Voorberg, ${ }^{4}$ Srinivas V. Kaveri ${ }^{1,2,3}$ and Sébastien \\ Lacroix-Desmazes ${ }^{1,2,3}$
}

${ }^{1}$ INSERM, UMR S 1138, Centre de Recherche des Cordeliers, Paris, France; ${ }^{2}$ Université Pierre et Marie Curie-Paris 6, UMR S 1138, Centre de Recherche des Cordeliers, Paris, France; ${ }^{3}$ Université Paris Descartes, UMR S 1138, Centre de Recherche des Cordeliers, Paris, France and ${ }^{4}$ Department of Plasma Proteins, Sanquin Research and Landsteiner Laboratory, Academic Medical Center, University of Amsterdam, the Netherlands.

\section{ABSTRACT}

$\mathrm{H}$ emophilia $\mathrm{A}$ is a rare hemorrhagic disorder caused by the lack of functional pro-coagulant factor VIII. Factor VIII replacement therapy in patients with severe hemophilia A results in the development of inhibitory anti-factor VIII IgG in up to $30 \%$ of cases. To date, immune tolerance induction, with daily injection of large amounts of factor VIII, is the only strategy to eradicate factor VIII inhibitors. This strategy is, however, efficient in only $60-80 \%$ of patients. We investigated whether blocking Bcell receptor signaling upon inhibition of Bruton tyrosine kinase prevents anti-factor VIII immune responses in a mouse model of severe hemophilia A. Factor VIII-naïve and factor VIII-sensitized factor VIII-deficient mice were fed with the selective inhibitor of Bruton tyrosine kinase, (R)-5amino-1-(1-cyanopiperidin-3-yl)-3-(4-[2,4-difluorophenoxyl] phenyl)-1H pyrazole-4-carboxamide (PF-06250112), to inhibit B-cell receptor signaling prior to challenge with exogenous factor VIII. The consequences on the anti-factor VIII immune response were studied. Inhibition of Bruton tyrosine kinase during the primary anti-factor VIII immune response in factor VIII-naive mice did not prevent the development of inhibitory anti-factor VIII IgG. In contrast, the anti-factor VIII memory B-cell response was consistently reduced upon treatment of factor VIII-sensitized mice with the Bruton tyrosine kinase inhibitor. The Bruton tyrosine kinase inhibitor reduced the differentiation of memory B cells ex vivo and in vivo following adoptive transfer to factor VIII-naïve animals. Taken together, our data identify inhibition of Bruton tyrosine kinase using PF-06250112 as a strategy to limit the reactivation of factor VIII-specific memory B cells upon rechallenge with therapeutic factor VIII.

\section{Introduction}

Hemophilia A is a rare X-linked hemorrhagic disorder that results from suboptimal levels of pro-coagulant factor VIII (FVIII). Treatment or prevention of bleeding is managed by replacement therapy using therapeutic FVIII, which restores coagulation. However, in up to $30 \%$ of patients with severe hemophilia A administration of exogenous FVIII is complicated by the development of anti-FVIII antibodies that neutralize FVIII pro-coagulant activity and are referred to as 'FVIII inhibitors'. ${ }^{1,2}$ To date, the most efficient strategy to eradicate inhibitors in inhibitor-positive patients with the severe form of the disease consists in repeated injections of high doses of FVIII and is referred to as 'immune tolerance induction' (ITI). Proposed mechanisms of action of ITI include the induction of protective anti-idiotypic antibodies that neutralize FVIII inhibitors, as observed in hemophilia A patients, ${ }^{3,4}$ and the inhibi- 
tion of FVIII-specific memory B cells, as suggested from experiments in FVIII-deficient mice. ${ }^{5}$ ITI is, however, prohibitively costly, requires extreme compliance from the patients and their families, and is successful in only 60$80 \%$ of cases. $^{6-8}$ Direct depletion of B cells with the antiCD20 antibody rituximab (Mabthera ${ }^{\circledR}$ ) is also used, although with limited success and unpredictable consequences in the long-term in populations of pediatric patients. ${ }^{9}$

The development of FVIII inhibitors results from the engagement of a classical T-cell-dependent immune respons $^{10}$ as evidenced by the presence of class-switched, high affinity anti-FVIII antibodies. B cells play key roles in primary $\mathrm{T}$-cell-dependent immune responses, by forming and sustaining germinal centers, by differentiating into antibody-secreting plasma cells and possibly, as recently suggested, as antigen-presenting marginal zone (MZ) B cells involved in the initial stages of activation of immune effectors. ${ }^{11}$ During recall responses, memory B cells can be reactivated upon antigen encounter and differentiate into plasma cells, replenish the memory B-cell pool or participate as key professional antigen-presenting cells owing to a higher prevalence of the cells and to the expression of a higher affinity antigen-specific B-cell receptor (BCR). ${ }^{12,13}$ Antigen-specific $B$ cells are thus potential targets to prevent primary or recall antigen-specific immune responses.

Engagement of a surface-exposed BCR by its cognate antigen triggers the formation of an intracellular signaling complex which enhances downstream signaling through the phosphorylation and ubiquitination of proteins. Bruton tyrosine kinase (BTK) is a key proximal and ratelimiting component of the signaling cascade critical for Bcell activation, proliferation and survival. ${ }^{14}$ This cytosolic Tec kinase is activated only when BCR signaling promotes its recruitment at the inner cell membrane. Activated BTK in turn phosphorylates the phospholipase $\mathrm{C} \gamma 2$, which leads to the downstream production of inositol triphosphate and diacylglycerol, resulting in calcium flux and finally to the activation of the NF- $\mathrm{kB}$ and NFAT-dependent pathways. ${ }^{16} \mathrm{BTK}$ is a strategic therapeutic target for B-cell malignancies that require BTK signaling for cell survival, and for autoimmune diseases associated with the presence of pathogenic autoantibodies such as rheumatoid arthritis ${ }^{15}$ or lupus. ${ }^{16}$ Several small-molecule inhibitors of BTK have been developed. ${ }^{17}$ (R)-5-amino-1-(1cyanopiperidin-3-yl)-3-(4-[2,4-difluorophenoxyl] phenyl)$1 \mathrm{H}$ pyrazole-4-carboxamide, or PF-06250112, is a selective potent, orally bioavailable, small-molecule inhibitor of BTK. PF-06250112 forms a covalent but reversible adduct with BTK upon binding to the Cys481 residue that is proximal to the ATP-binding pocket. ${ }^{18}$ Using a mouse model of severe hemophilia A, we evaluated the therapeutic potential of BTK inhibition by PF-06250112 on the development of a primary anti-FVIII immune response and on the FVIII-specific memory B-cell recall response.

\section{Methods}

\section{PF-06250112 formulation}

For in vitro studies, PF-06250112 (Pfizer, New York, NY, USA) was solubilized at $1 \mathrm{mg} / \mathrm{mL}$ in dimethylsulfoxide (Sigma-Aldrich, St Louis, MO, USA). For per os administration, PF-06250112 was prepared in $0.5 \%$ methylcellulose, $0.5 \%$ hydroxypropylmethylcellulose acetate succinate $\mathrm{H}$ grade and $20 \mathrm{mM}$ Tris at $\mathrm{pH}$ 7.4.

\section{Flow cytometry}

BTK inhibition with PF-06250112 was evaluated on splenocytes labeled with anti-CD86-FITC (BD Pharmingen, San Jose, CA, USA), and anti-B220-PE (BioLegend, San Diego, CA, USA). Phenotypic analyses were performed using anti-CD4-Alexa 700, anti-CD19-Pacific blue (Biolegend), anti-CD 45-APC (eBiosciences, San Diego, CA, USA); anti-CD3e-FITC, anti-CD11b-PE (BD Pharmingen), anti-CD21-APC Cy7, anti-CD23-PE Cy7 and antiGL7 Alexa 488 (Biolegend). Fluorescence activated cell sorting analysis was done on live cells using BD LSRII and FACSDiva software.

\section{Treatment of factor VIII-deficient mice}

Seven to 11 week-old exon 16 FVIII-deficient mice on a C57BI/6 background (a gift from Prof. H.H. Kazazian, Department of Genetics, University of Pennsylvania School of Medicine, PA, USA) were handled in agreement with ethical authority guidelines (experimentation on mice was approved by the Animal Ethics Committee, authorization \#02058.04 granted by the Direction Générale de la Recherche et de l'Innovation). PF-06250112 and analogs have half-lives of about $7 h^{18,19}$ For preventive treatment, mice were fed for 5 consecutive days per week, during 4 weeks, with PF-06250112 $(15 \mathrm{mg} / \mathrm{kg})$ or vehicle in order to cover about $10 \mathrm{FVIII}$ half-lives..$^{20}$ Mice were injected with human recombinant $B$ domain-deleted FVIII (0.5 $\mu \mathrm{g}$ BDD-FVIII, Refacto, Pfizer) once a week, $2 \mathrm{~h}$ after the second feed of the week. Mice were bled 5 days after the fourth FVIII injection. To investigate the effect of PF06250112 on recall immune responses to FVIII, mice were injected intravenously with $0.5 \mu \mathrm{g}$ of BDD-FVIII or phosphate-buffered saline (PBS) once a week for 4 weeks. Ninety days after the last FVIII injection, FVIII-sensitized mice with anti-FVIII circulating antibodies were fed for 5 days a week, during 2 weeks, with PF$06250112(15 \mathrm{mg} / \mathrm{kg})$ or vehicle. Only one challenge with FVIII was performed with $1 \mu \mathrm{g}$ of BDD-FVIII, $2 \mathrm{~h}$ after the second day of the first week of feeding. Mice were bled before and 7 and 14 days after FVIII challenge.

\section{Evaluation of anti-factor VIII immune responses}

Anti-FVIII IgG in mouse serum were measured by enzymelinked immunosorbent assay (ELISA) and FVIII inhibitory titers were measured with a chromogenic assay (Siemens, Marburg, Germany). ${ }^{21}$ Proliferation of splenocytes was assessed in 96-well plates $\left(0.25 \times 10^{6}\right.$ cells/well) with concanavalin A (Sigma) or BDDFVIII for $72 \mathrm{~h} .{ }^{22}$ Cell proliferation was measured by incorporation of $\left.{ }^{3} \mathrm{H}\right]$-thymidine $(0.5 \mu \mathrm{Ci} /$ welli) for an additional $18 \mathrm{~h}$, using a $\beta$ counter (Microbeta 1450, Perkin Elmer).

\section{Stimulation of adoptively transferred memory B cells}

Spleens from FVIII-sensitized mice that had developed detectable anti-FVIII IgG (typically $80 \%$ of the mice) were collected 7 days after the fourth injection with $1 \mu \mathrm{g}$ of BDD-FVIII. After lysis of erythrocytes, splenocytes were pooled and plasma cells were depleted using a goat anti-mouse CD138 polyclonal antibody (BD Pharmingen), conjugated to anti-goat IgG-coated Dynabeads (Thermo Fisher, Waltham, MA, USA). ${ }^{23}$ FVIII-naive FVIII-deficient mice were then injected intravenously with $10^{7}$ CD138-depleted splenocytes. Feeding of mice with PF-06250112 or vehicle was initiated $24 \mathrm{~h}$ after adoptive transfer for 5 consecutive days a week during 2 weeks and $1 \mu \mathrm{g}$ of BDD-FVIII was injected intravenously only once $2 \mathrm{~h}$ after the first feed. Mice were bled 14 days after the FVIII injection.

\section{Ex vivo memory B-cell differentiation assay}

Pooled splenocytes from five FVIII-sensitized mice having developed anti-FVIII IgG were cultured at $1.5 \times 10^{6}$ cells $/ \mathrm{mL}$ in 
RPMI-1640, with 10\% fetal calf serum (Thermo Fisher), $100 \mathrm{U} / \mathrm{mL}$ penicillin, $100 \mu \mathrm{g} / \mathrm{mL}$ streptomycin, and $50 \mu \mathrm{M}$ 2-mercaptoethanol without CD138 depletion for 6 days. At day 0, PF06250112 or vehicle was added at different concentrations. FVIII $\left(1 \mu \mathrm{g} / \mathrm{mL}\right.$ Advate ${ }^{\varpi}$, Shire, Dublin, Ireland) was added to the culture $2 \mathrm{~h}$ later. Advate was used instead of Refacto to follow the seminal protocol established by Hausl et al. as closely as possible..$^{23}$ Of note, Refacto and Advate present with the same immunogenicity in FVIII-deficient mice. ${ }^{21,24}$ After 6 days, the formation of FVIII-specific antibody-secreting plasma cells was assessed by an enzymelinked immunospot (ELISPOT) assay with FVIII-coated plates (0.5 $\mu \mathrm{g}$ Advate/well). After $2 \mathrm{~h}$ of blocking with $10 \%$ fetal calf serum in RPMI medium, cells were incubated on the membrane and cultured overnight at $37^{\circ} \mathrm{C}$ in $5 \% \mathrm{CO}_{2}$. After washing with PBS, $0.1 \%$ Tween 20, antibodies were detected using a goat anti-mouse IgG alkaline phosphatase-conjugated antibody (Southern Biotech, Birmingham, Alabama, USA), and antibody-secreting plasma cells were revealed with Sigmafast 5-bromo-4-chloro-3-indolyl phosphate/nitro blue tetrazolium (BCIP/NBT) tablets (Sigma). Plates were scanned on an ImmunoSpot Analyzer (CTL, Shaker Heights, $\mathrm{OH}, \mathrm{USA}$ ). Spots were automatically counted by ImmunoSpot software using the SmartCount ${ }^{\mathrm{TM}}$ and Autogate ${ }^{\mathrm{TM}}$ functions.

\section{Statistical analysis}

The statistical analysis was performed using the non-parametric two-tailed Mann-Whitney U test with a 95\% confidence interval. $P$ values $\leq 0.05$ were considered statistically significant (ns: not significant). GraphPad Prism version 5.0 (GraphPad Software, San Diego, CA, USA) was used for the statistical analysis.

\section{Results}

\section{PF-06250112 inhibits B-cell receptor signaling}

BCR engagement initiates an intracellular signaling cascade that induces the BTK-dependent activation of $B$ cells. ${ }^{14}$ PF-06250112 has recently been described to inhibit BCR-mediated B-cell signaling, activation and proliferation. ${ }^{18}$ We confirmed the effect of PF-06250112 on splenic $\mathrm{B}$ cells by monitoring the upregulation of CD86 in response to B-cell triggering with anti-IgM or anti-IgD for in vitro and in vivo assays, respectively. Pre-treatment of purified splenic B cells by PF-06250112 prevented, in a dose-dependent manner, the induction of CD86 expression on $\mathrm{B}$ cells upon stimulation with anti-IgM $\mathrm{F}\left(\mathrm{ab} \mathrm{b}^{\prime}\right)_{2}$ fragments (Figure 1A). It did, however, marginally affect CD86 expression upon stimulation of the cells with an anti-CD40 antibody. The calculated half maximal inhibitory concentration $\left(\mathrm{IC}_{50}\right)$ was $1.1 \pm 0.6 \mathrm{nM}$ (Figure $1 \mathrm{~A}$, inset), which is in agreement with previous observations. ${ }^{18}$ The in vivo validation of the effect of PF-06250112 was performed using an anti-IgD antiserum instead of the antiIgM antibody in order to avoid quenching of the triggering antibody by endogenous circulating IgM. The treatment of FVIII-deficient mice with PF-06250112 $2 \mathrm{~h}$ prior to the injection of the anti-IgD antiserum prevented anti-IgDmediated CD86 induction, as measured ex vivo on splenic $\mathrm{B}$ cells (Figure 1B), and only marginally affected antiCD40-mediated CD86 induction. The dose of $15 \mathrm{mg} / \mathrm{kg}$ of PF-06250112 was sufficient to prevent induction of CD86
A

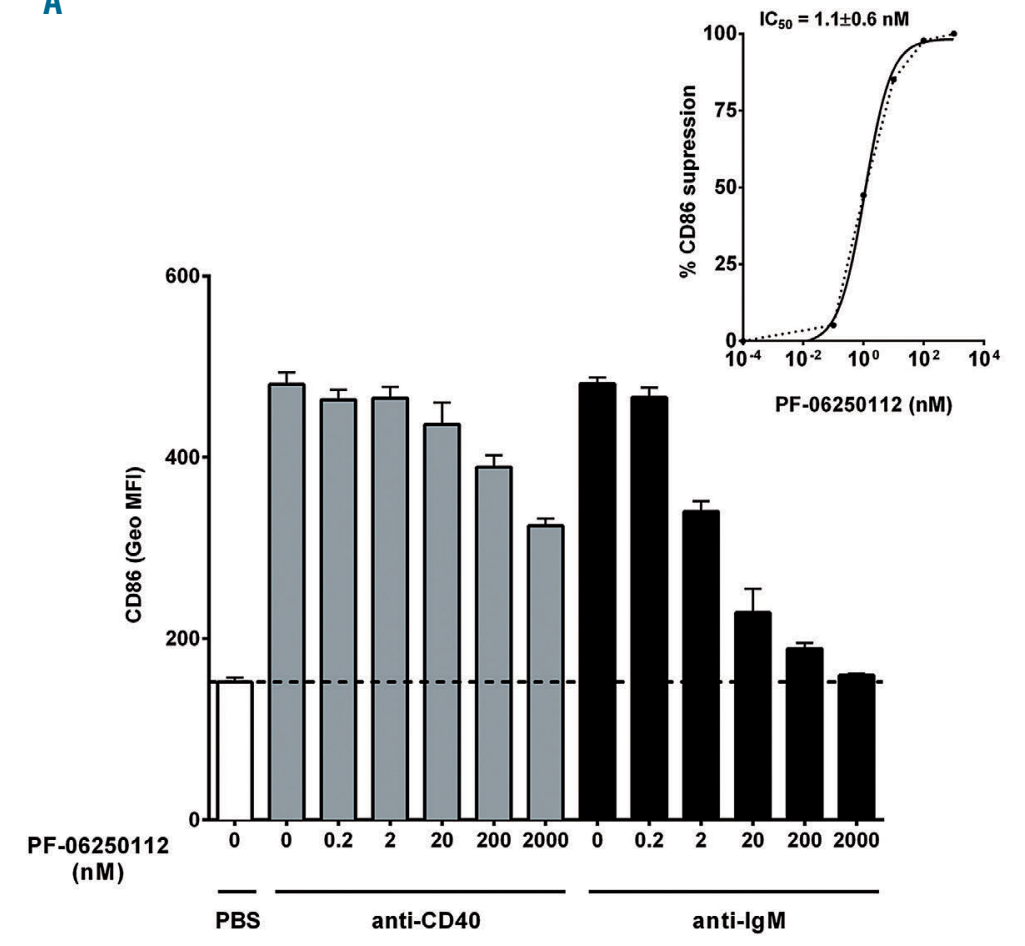

B

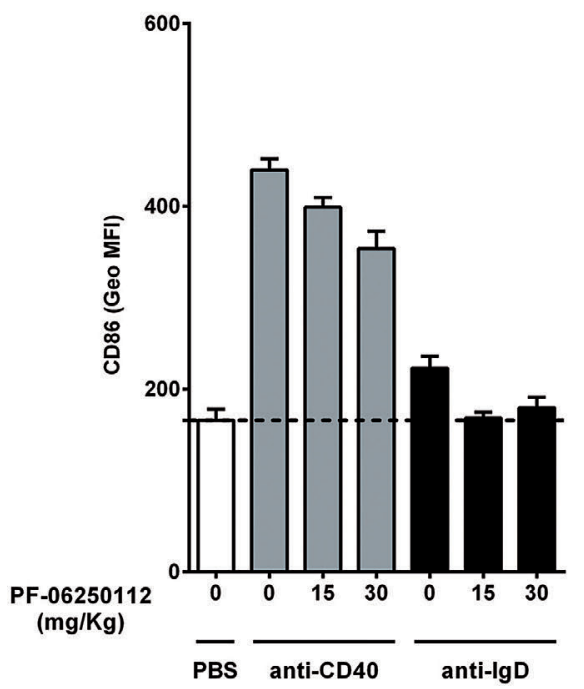

Figure 1. Inhibition of splenic B-cell activation by PF-06250112. (A) Splenic B cells from C57BI/6 mice, purified by negative selection, were plated in RPMI, 10\% fetal calf serum and treated with PF-06250112 or vehicle (dimethylsulfoxide) for $2 \mathrm{~h}$. F(ab') ${ }_{2}$ fragments of goat anti-mouse lgM (10 $\mu \mathrm{g} / \mathrm{mL}$ ) or a monoclonal hamster anti-mouse CD40 antibody ( $5 \mu \mathrm{g} / \mathrm{mL}$ ) were added. After $24 \mathrm{~h}$, the expression of CD86 by live B220+ cells was analyzed by flow cytometry. Results are representative of two independent experiments performed in triplicate (mean \pm SD). Treatment of B cells in vitro with PF-06250112 suppressed induction of CD86 expression with an $\mathrm{IC}_{50}$ of $1.1 \pm 0.6 \mathrm{nM}$ (Inset). (B) C57BI/ 6 mice were fed with PF-06250112 or vehicle. After $2 \mathrm{~h}$, goat anti-lgD antiserum (400 $\mu \mathrm{L}$, eBiosciences), or rat anti-mouse $\mathrm{CD} 40$ lgG (100 $\mu \mathrm{g}$, Biolegend) was injected intraperitoneally. Eighteen hours later, mice were sacrificed and the expression of CD86 by live splenic B220 $\mathrm{B}$ cells was analyzed by flow cytometry. Results are representative of two independent experiments performed with three mice per group (mean \pm SD). 
expression in the mice and was used for further experiments.

\section{Bruton tyrosine kinase inhibition does not prevent a primary anti-factor VIII immune response}

We then investigated the potential of PF-06250112 to prevent the development of a primary anti-FVIII immune response in FVIII-deficient mice (Figure 2A). The effect of 4 weeks of treatment with PF-06250112 was first evaluated on the splenic B- and T-cell compartments of FVIII- injected mice. Analysis by flow cytometry revealed that chronic inhibition of BTK with PF-06250112 resulted in an increase in $\mathrm{CD}_{11} \mathrm{~b}^{+}$cells $(P=0.040)$ (Figure $\left.2 \mathrm{~B}\right)$, which include monocytes, macrophages and natural killer cells, and in a significant decrease in $\mathrm{CD} 4^{+} \mathrm{T}$ cells $(P=0.031)$ and in different B-cell subsets, including follicular and $M Z B$ cells $(P=0.038)$ (Figure $2 \mathrm{C})$. Although statistically significant, changes in percentages of the cell populations were biologically marginal. The anti-FVIII IgG titers measured after the fourth injection of FVIII in PF-06250112-treated

A

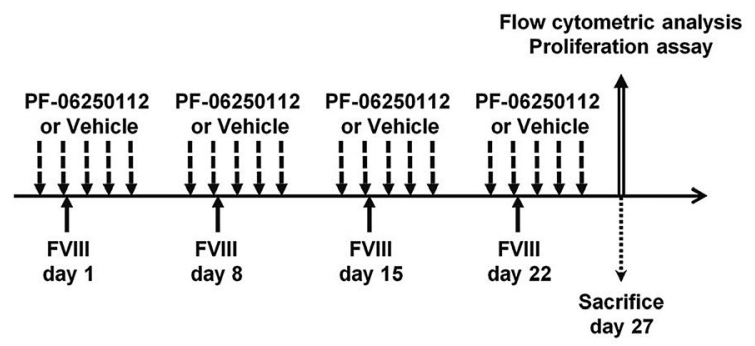

B

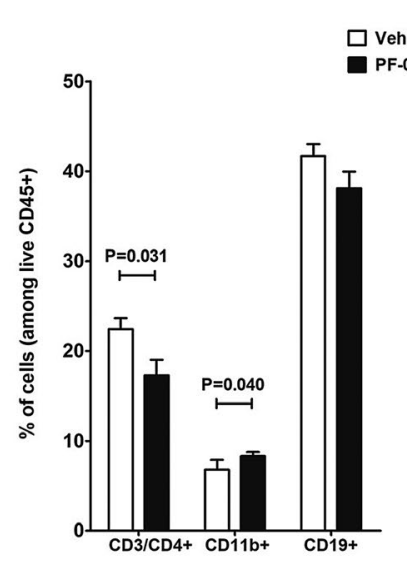

$E$

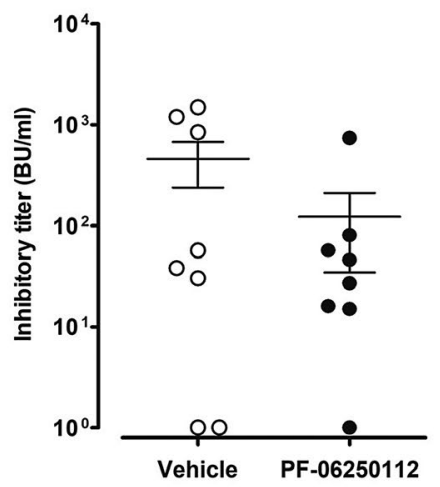

C

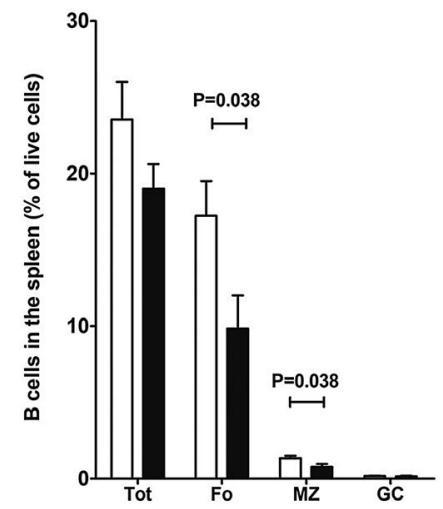

$\mathbf{F}$

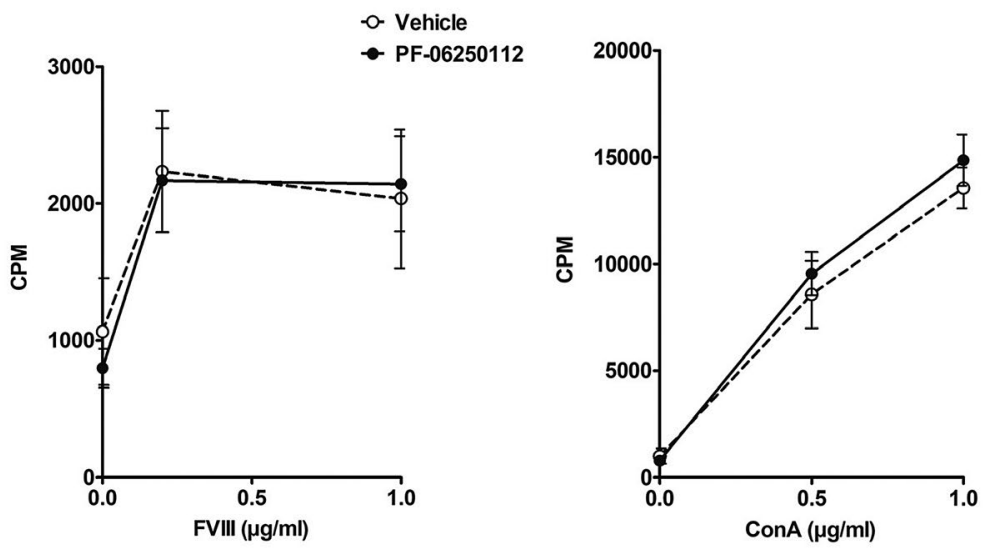

Figure 2. Treatment with PF-06250112 does not prevent the onset of a primary anti-factor VIII immune response. (A) Experimental scheme for the preventive treatment of FVIII-deficient mice. Mice were fed with PF-06250112 (15 mg/kg) or vehicle for 5 days a week, and injected with FVIII once a week, $2 \mathrm{~h}$ after the second feed of the week. Mice were sacrificed 5 days after the fourth injection of FVIII (day 27). Spleens and sera were recovered. (B and C) At sacrifice, the isolated splenocytes were labeled with anti-CD45, anti-CD11b, anti-CD19, anti-CD3 and anti-CD4 antibodies (\% of live CD45 ${ }^{+}$cells) (B). Follicular B cells (Fo) were identified as CD19+ ${ }^{+}$D23 high $C D 21^{\text {low }}$, marginal zone B cells (MZ) as CD19+CD21 high $C D 23^{\text {low }}$, and germinal center B cells (GC) as CD19+GL7 $7^{+} \%$ of live cells) (C). (D and E) Anti-FVIII IgG titers (D) and inhibitory titers (E) were measured in the sera of mice by ELISA with the mouse monoclonal anti-FVIII IgG mAb6 as a standard (expressed in arbitrary units, $\mathrm{AU}$ ), and chromogenic assay, respectively. ( $\mathrm{F}$ and $\mathrm{G})$ Splenocytes were incubated for $72 \mathrm{~h}$ with $\mathrm{FVIII}(\mathrm{F})$ or with concanavalin $\mathrm{A}(\mathrm{ConA})(\mathrm{G})$. The incorporation of tritiated thymidine is depicted as counts per minute (CPM) after an additional $18 \mathrm{~h}$ of incubation (mean \pm SEM). Data are representative of two independent experiments with nine mice per group. 
mice $(565 \pm 170 \mathrm{AU}$, mean \pm standard error of mean) (Figure 2D) were not statistically different from those in vehicle-treated mice $(1133 \pm 376 \mathrm{AU}, P=0.488)$. Similarly, inhibitory titers did not differ statistically between PF06250112-treated mice (123 $\pm 88 \mathrm{AU}$ ) (Figure 2E) and control mice $(457 \pm 219 \mathrm{AU}, P=0.572)$. The capacity of splenic $\mathrm{T}$ cells to proliferate in the presence of FVIII or concanavalin A was similar in the two groups of mice (Figure $2 \mathrm{~F}, \mathrm{G})$. Thus, inhibition of BTK at the time of FVIII injection does not prevent the onset of a primary anti-FVIII immune response.

\section{Bruton tyrosine kinase inhibition alters the memory factor VIII-specific B-cell response}

We investigated the effect of BTK inhibition in the context of a memory anti-FVIII B-cell response, in which the FVIII-specific BCR in principle have a higher affinity for FVIII than BCR of naive B cells. FVIII-deficient mice were injected with FVIII once a week for 4 weeks, and then left untouched for 90 days to allow the spontaneous elimina- tion of FVIII-specific short-lived plasmocytes. ${ }^{25}$ FVIII-sensitized mice were then fed with vehicle or PF-06250112 and treated with FVIII as described in Figure 3A. AntiFVIII IgG titers measured prior to FVIII re-challenge were heterogeneous among mice (Figure $3 \mathrm{~B}$ ), as previously described. ${ }^{21,26,27}$ The levels of anti-FVIII IgG depicted in Figure $3 \mathrm{C}$ were, therefore, normalized with respect to the initial levels of anti-FVIII IgG measured for each individual mouse. Feeding mice with PF-06250112 significantly reduced the increase of the anti-FVIII IgG response, as compared to that in control mice (Figure 3C).

We then exploited an alternative model in order to study the effect of PF-06250112 in the absence of a potential bias provided by the presence of plasma cells and circulating anti-FVIII IgG. Splenocytes from FVIII-treated mice or -naïve mice were depleted of $\mathrm{CD} 138^{+}$plasmocytes and adoptively transferred to FVIII-naïve FVIII-deficient mice as previously described. ${ }^{23}$ Feeding of the recipient mice with PF-06250112 or vehicle was initiated on the next day, and one injection of FVIII was given $2 \mathrm{~h}$ after the

A

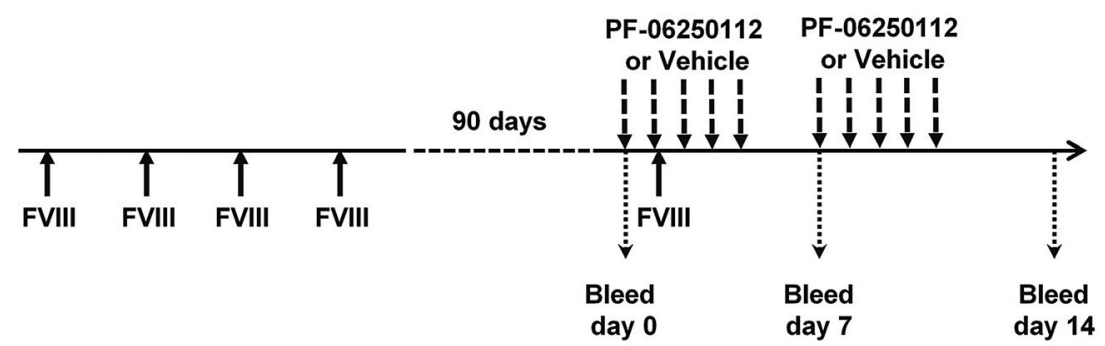

B

C

-O- Vehicle

PF-06250112

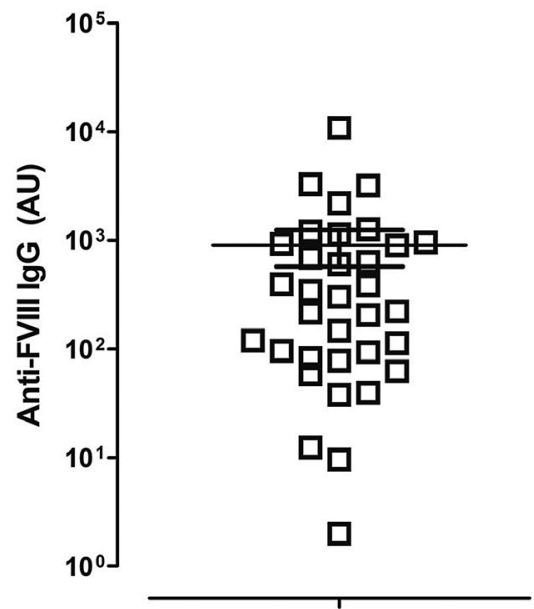

day 0

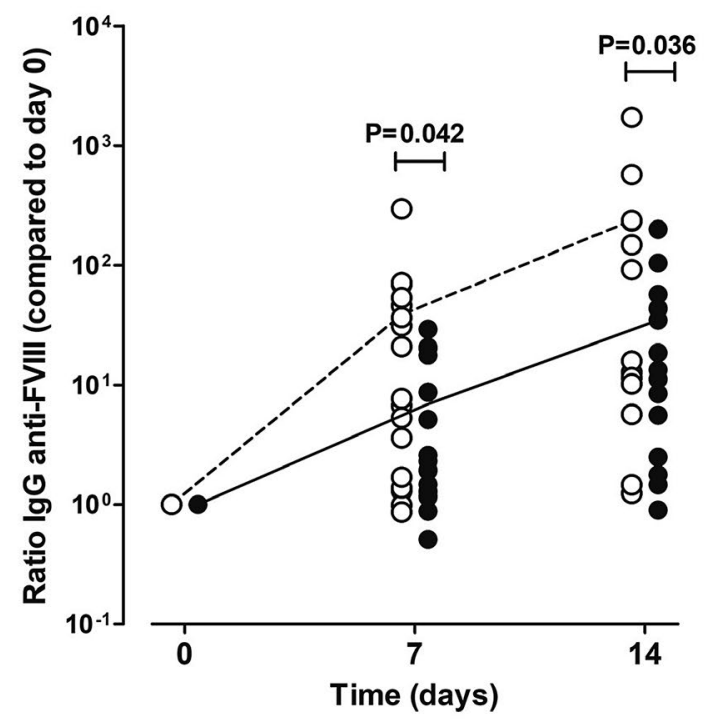

Figure 3. Treatment with PF-06250112 controls the recall response to factor VIII. (A) FVIII-deficient mice were injected with FVIII once a week for 4 weeks. After 90 days, mice were fed for 5 days a week, during 2 weeks, with PF-06250112 or vehicle, and injected with FVIII only once, 2 h after the second day feed. (B) Levels of anti-FVIII IgG were assessed by enzyme-linked immunosorbent assay using the mouse monoclonal anti-FVIII antibody mAb6 as a standard. Mice were then randomly attributed to either the PF-06250112- or the vehicle-fed groups. (C) Levels of anti-FVIII IgG were measured 7 and 14 days after the last injection of FVIII. IgG levels were normalized with respect to the initial levels of anti-FVIII IgG of each respective mouse measured at Bleed 0 . Graphs depict means \pm SEM of three independent experiments with a total of 17 mice/group. 
first feed (Figure 4A). The treatment of mice with PF06250112 prevented the production of anti-FVIII IgG as compared to that in control mice $(0.9 \pm 0.3$ versus 124.0 $\pm 115.7, P=0.011$ ) (Figure 4B). Anti-FVIII IgG titers in PF-06250112-treated mice injected with FVIII were similar to those of control mice adoptively transferred with splenocytes from FVIII-sensitized mice injected with PBS and to those of control mice adoptively transferred with splenocytes from FVIII-naïve and FVIII-injected mice. We further performed re-stimulation of FVIII-specific memory $\mathrm{B}$ cells ex vivo. Splenocytes from FVIII-sensitized FVIIIdeficient mice having developed a humoral response to FVIII were isolated and pre-treated with PF-06250112 or vehicle before stimulation with FVIII. After 6 days of culture, FVIII-specific antibody-secreting plasma cells were measured by ELISPOT. A statistically significant dosedependent reduction of antibody-secreting plasma cell formation was observed when splenocytes were pre-incubated with PF-06250112 as compared to splenocytes preincubated with vehicle, prior to stimulation with FVIII $(P \leq 0.003)$ (Figure 5). Thus, inhibition of BTK prevents the activation of the FVIII-specific memory B-cell response.

\section{Discussion}

The occurrence of FVIII inhibitors following FVIII replacement therapy remains a major clinical and societal challenge in hemophilia A. B cells are a key effector of the anti-FVIII immune response. Depending on their subtype

A

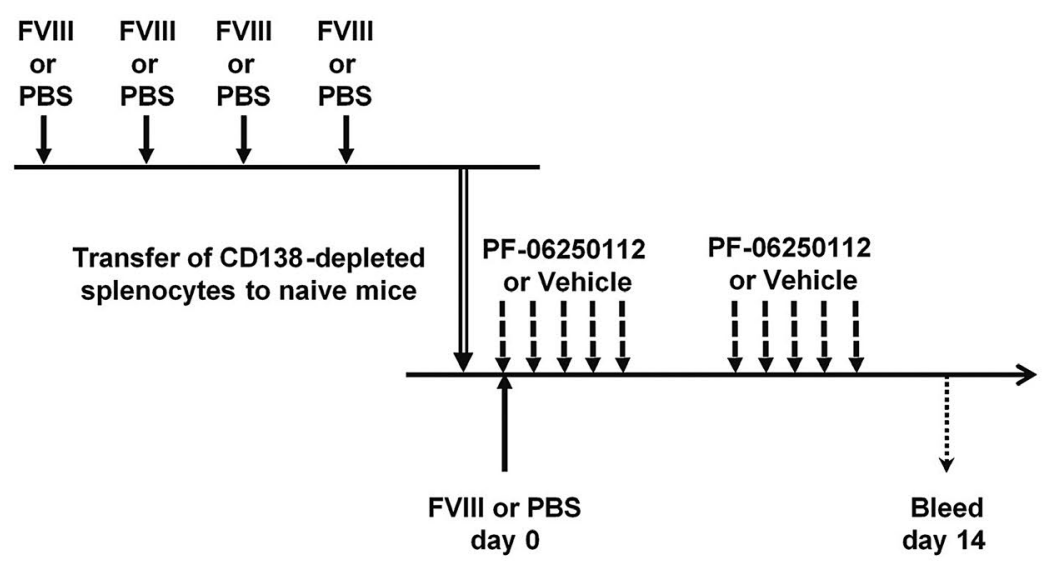

B

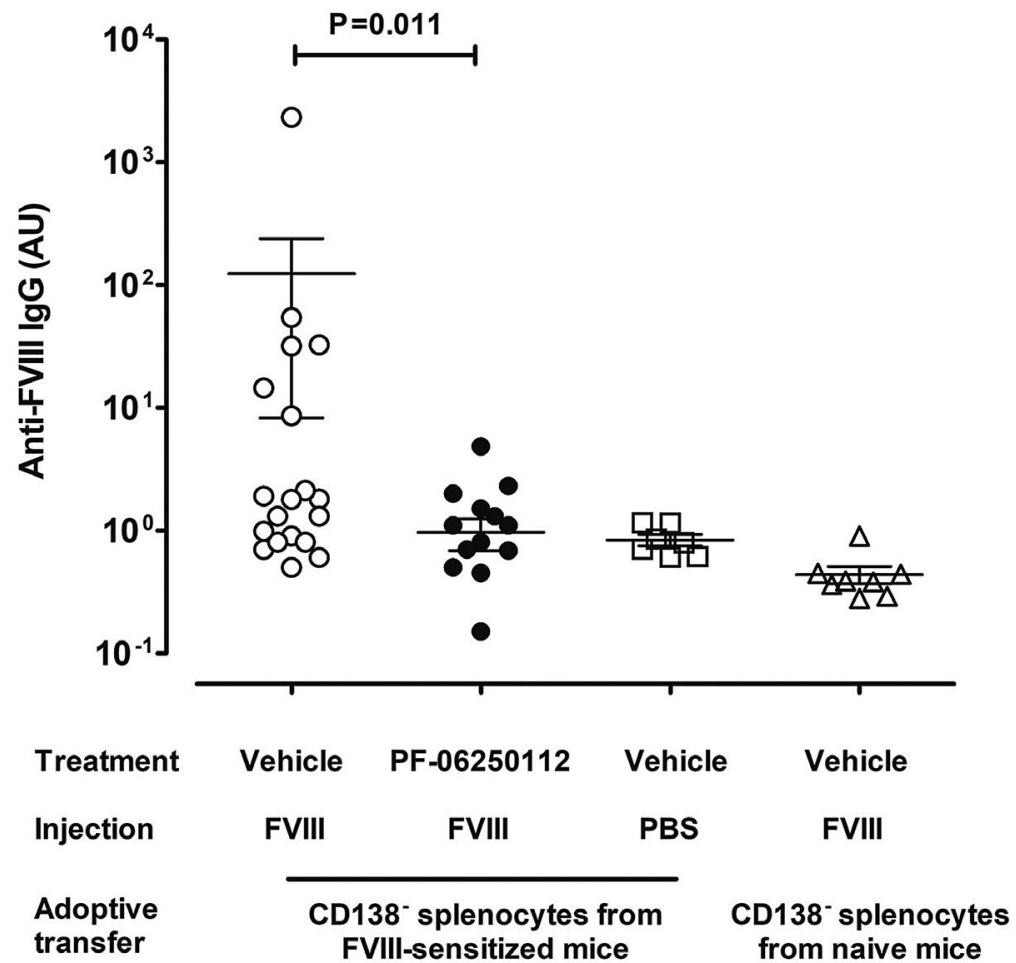

Figure 4. Treatment with PF-06250112 inhibits the anti-factor VIII memory B-cel response. (A) FVIII-deficient mice were injected with phosphate-buffered saline (PBS) or FVIII once a week for 4 weeks. Seven days after the last injection, mice were sacrificed and spleens were collected and pooled. CD138-depleted splenocytes from FVIII-treated or naïve (PBStreated) FVIII-deficient mice were adoptively transferred to naïve FVIII-deficient mice. From the next day onwards, host FVIII-deficient mice were fed during 2 weeks with $15 \mathrm{mg} / \mathrm{kg}$ of PF061250112 (18 mice) or vehicle (20 mice), daily for 5 days. Two control groups were injected with PBS or were adoptively transferred with splenocytes from naïve mice (7 mice per group). Mice were injected with FVIII or PBS only once 2 $\mathrm{h}$ after the first feed. (B) Levels of anti-FVIII IgG were measured by enzyme-linked immunosorbent assay 14 days after FVIII challenge. Means \pm SEM are depicted on the graph. 
and localization and depending on the stage of the immune response, B cells play different roles as (i) antigenpresenting cells either in the initiation phase of an immune response (i.e., MZ B cells involved in FVIII capture and trafficking in the spleen), ${ }_{11}^{11}$ or in recall responses (higher number of FVIII-specific memory B cells with high-affinity FVIII-specific BCR), and (ii) precursors of antibodysecreting plasma cells (that produce FVIII inhibitors) localized in the spleen or in the bone marrow. Therefore, B cells represent an ideal therapeutic target either to prevent the initiation of anti-FVIII immune responses or to eradicate ongoing responses in inhibitor-positive patients. Incidentally, the only strategies known to eradicate FVIII inhibitors in patients' target B cells. ITI was shown to favor the development of anti-idiotypic antibodies that neutralize FVIII inhibitors, ${ }^{3,4}$ and, at least in mice, eliminate FVIII-specific memory B cells. ${ }^{5}$ Likewise, the therapeutic anti-CD20 antibody rituximab specifically targets CD20expressing naïve and memory $B$ cells, thus preventing the replenishment of the pool of plasma cells upon re-challenge with therapeutic FVIII. Both strategies fail to target long-lived plasma cells that reside in niches in the bone marrow and lack expression of CD20 and of the BCR. ${ }^{28}$ Attempts to target plasma cells in FVIII-deficient mice using either inhibitors of the proteasome ${ }^{29}$ or cocktails of immunosuppressive agents $\mathrm{s}^{30}$ have met with limited success or lack of antigen specificity. Here we investigated a new approach to prevent the activation of antigen-specific $B$ cells by inhibiting BTK, a kinase involved in upstream $B C R$ signaling. Inhibition of BTK targets only those B cells that are activated at the time of administration of therapeutic FVIII, thus providing some degree of specificity for FVIII.

We first validated that, upon BCR triggering, PF06250112 blocks $B C R$ signaling in vitro and in vivo by measuring the induction of CD86 expression, a co-stimulation molecule involved in anti-FVIII immune responses. ${ }^{31} \mathrm{PF}-$ 06250112 inhibited $\mathrm{BCR}$ signaling in vitro with an $\mathrm{IC}_{50}$ of about $1 \mathrm{nM}$, a value close to that reported previously. ${ }^{18} \mathrm{PF}-$ 06250112 used at $15 \mathrm{mg} / \mathrm{kg}$ also inhibited the induction of CD86 in vivo following stimulation of splenic B cells with an anti-IgD serum. A marginal effect of PF-06250112 was observed on B cells stimulated by CD40 ligation, a BCRindependent pathway. This moderate alteration of CD40 signaling had also been reported in the case of PCI-32765, another BTK inhibitor; a possible interference of BTK inhibitors on CD40-induced NF-kB-signaling was

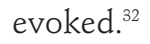

As previously reported in an experimental model of systemic lupus erythematosus ${ }^{18}$ or using immunization of mice with the T-dependent model antigen SRBC ${ }_{19}^{19}$ the regular per os administration of PF-06250112 to FVIII-deficient mice led to a statistically significant decrease in the percentages of $\mathrm{MZ}$ and follicular B cells. In contrast to the latter reports however, there was no change in percentages of splenic germinal center B cells, possibly owing to the use of a different antigen or of a different disease model. In our hands, treatment of FVIII-deficient mice with PF06250112 failed to prevent the onset of a primary antiFVIII immune response. Exogenously administered FVIII was previously shown to closely associate with $M Z$ macrophages and MZ B cells. ${ }^{11,33,34}$ The depletion of $M Z$ macrophages or $M Z B$ cells was independently shown to delay the onset of an anti-FVIII immune response. ${ }^{11,33}$ However, it is not clear whether reduced immune responses to FVIII following depletion of $M Z$ macrophages or B cells result from the direct involvement of these cells in FVIII internalization and presentation to $T$ cells, or trafficking to the germinal center, or from a mere disruption of the splenic architecture. ${ }^{35}$ The lack of effect of chronic BTK inhibition on the development of primary anti-FVIII humoral responses, despite an alteration of peripheral B-cell populations, including MZ B cells, suggests that $M Z$ macrophages are the principal antigen-presenting cells at play in the onset of primary anti-FVIII immune responses, at least in mice. PF-06250112 feeding was also associated with a modest decrease in percentages of $\mathrm{CD}^{+} \mathrm{T}$ cells. PF-06250112 has been shown to be 10,000-fold more specific for BTK than for interleukin-2inducible T-cell kinase (ITK). ${ }^{18}$ In addition, there is no modulation of splenic T-cell populations in BTK-deficient mice. ${ }^{14}$ Hence, the decrease in the percentage of $\mathrm{CD}^{+} \mathrm{T}$ cells probably does not reflect a direct effect of PF06250112 on T cells in FVIII-sensitized mice, but rather a modulation of $\mathrm{T}$-cell homeostasis consequent to a decrease in splenic follicular and MZ B cells. This illustrates a possible moderate off-target effect of PF-06250112 in naive mice. Signaling through CD40 and CD40L is essential for the onset of primary immune responses, including in the case of therapeutic FVIII. ${ }^{36,37}$ The lack of effect of PF-06250112 on the primary anti-FVIII immune response presumably reflects the lack of effect of BTK inhibition on CD40 signaling.

The inhibition of BTK using PF-06250112 was able to

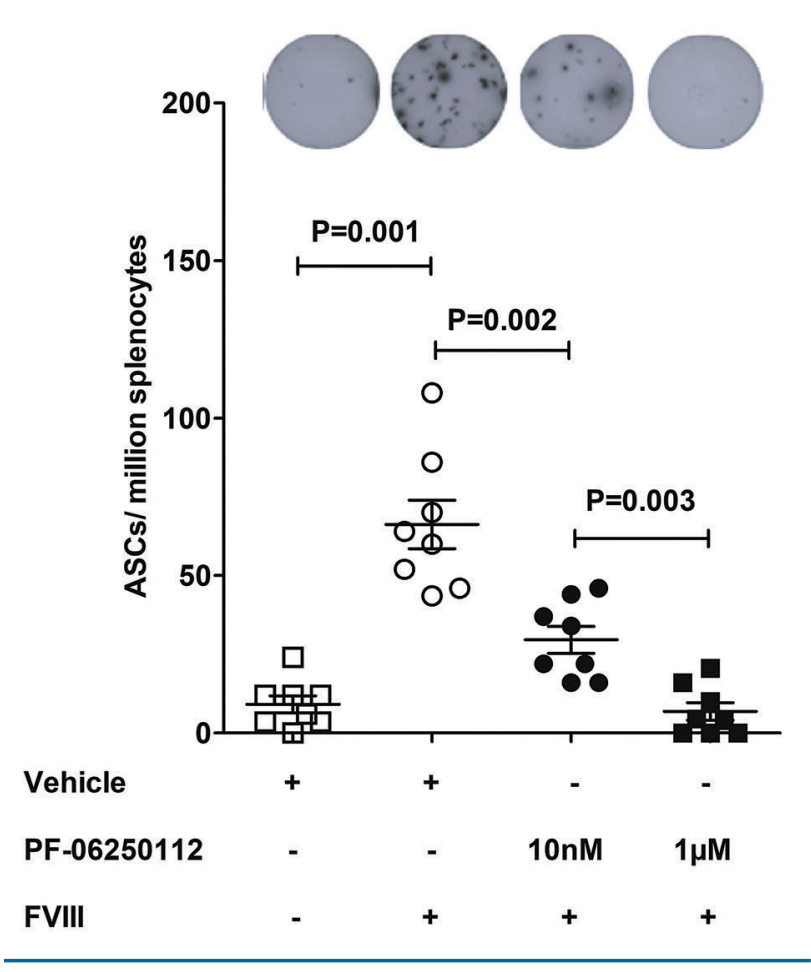

Figure 5. PF-06250112 inhibits the ex vivo differentiation of FVIII-specific memory B cells into antibody-secreting plasma cells. Splenocytes from FVIIIsensitized FVIII-deficient mice having developed a humoral response to FVIII were isolated 14 days after the last injection of FVIII. Pooled splenocytes were cultured for 6 days in the presence of $1 \mathrm{ug} / \mathrm{mL}$ FVIII. Splenocytes were incubated with vehicle or PF-06250112 $2 \mathrm{~h}$ before adding FVIII. At day 6, newly differentiated anti-FVIII antibody-secreting plasma cells (ASCs) were detected by an enzyme-linked immunospot assay. The graph depicts means \pm SEM. 
limit the memory B-cell response towards therapeutic FVIII. We first demonstrated that the inhibition of BTK in primed mice limits the increase in anti-FVIII IgG after a single re-challenge with FVIII. Plasma cells do not express $\mathrm{BCR}$ at their membrane and are, therefore, insensitive to BTK inhibition. ${ }^{19,38}$ The continuous endogenous production of anti-FVIII IgG by resident plasma cells may have introduced a bias in our experimental setup. Indeed, the formation of immune complexes between circulating anti-FVIII IgG and the administered FVIII neutralizes FVIII and alters its immunogenicity. ${ }^{39}$ In addition, immune complexes between FVIII and anti-FVIII IgG facilitate FVIII internalization by dendritic cells ${ }^{40}$ and could skew the target antigen-presenting cell population from memory B cells to dendritic cells or macrophages. In support of our initial observation, however, inhibition of BTK also prevented the in vivo re-activation of FVIII-specific memory B cells following adoptive transfer to FVIII-naïve mice and administration of FVIII, as well as the ex vivo differentiation of memory B cells into antibody-secreting plasma cells. Immune responses to FVIII in FVIII-deficient mice are notoriously heterogenous..$^{21,26,27}$ This is illustrated by the fact that $80 \%$ of the mice developed primary immune responses to FVIII, and that memory responses were heterogenous in the three experimental models used in the present study. Of note, although the effect of the inhibition of BTK on the anti-FVIII memory response was heterogenous among mice, results from all three experimental models showed a significant reduction in the intensity of the anti-FVIII memory response. Our finding that BTK inhibition was efficient in blocking anti-FVIII recall but not primary immune responses is reminiscent of recent observations. Chronic inhibition of BTK with an analog of PF-06250112 was shown to prevent immune responses to T-independent antigens or to T-dependent antigens only provided that BCR had a strong affinity for the antigen, and provided that antigen ligation induced a strong signaling of the BCR. ${ }^{14,19}$ Memory B cells generally express BCR of high affinity for their cognate antigen owing to affinity maturation in the germinal centers. In the case of the anti-FVIII B-cell response, the rare human monoclonal anti-FVIII IgG studied to date were obtained following immortalization of memory B cells from inhibitor-positive patients. The affinity of the anti-C2 domain IgG4k $\mathrm{BO} 2 \mathrm{C} 11$ for $\mathrm{FVIII}^{41}$ is $10^{-11} \mathrm{M}^{-1}$ and that of the anti-C1 domain IgG4k LE2E9 is greater than the affinity of von Willebrand factor for FVIII (i.e., $\left.\mathrm{K}_{D}<0.1 \mathrm{nM}\right){ }^{42}$ Likewise, the affinity of polyclonal anti-FVIII IgG from inhibitorpositive patients was described to be in the low nanomolar range. ${ }^{43}$ Indirectly, the efficacy of PF-06250112 at blocking the recall anti-FVIII immune response confirms that FVIII-specific memory B cells express high affinity BCR.

A strong predictor of ITI failure is the intensity of the inhibitory titer peak that is reached within the 2 weeks that follow ITI initiation. ${ }^{45}$ The molecular and cellular mechanisms that underlie the reduced efficiency of ITI when the inhibitor peak is high after initiation of ITI are unknown. In particular, it is not understood whether a high level of circulating FVIII inhibitor reflects the quantitative or qualitative properties of the circulating anti-FVIII IgG, the affinity for FVIII of the BCR of memory B cells or the number of FVIII-specific memory B cells. Although the experimental protocols employed in the present work do not reflect the clinical situation, and although no animal model of ITI has been validated yet, we propose here that the inhibition of BTK-dependent BCR signaling as an adjunct therapy in patients starting ITI could increase the chances of the ITI being a success by preventing the reactivation of FVIII-specific memory B cells. Furthermore, the potential toxicity of PF-06250112 could be reduced by targeting the compound to FVIII-specific B cells using CD22L/FVIII-coated nanoparticles, ${ }^{44}$ thus paving the way towards their use in hemophilia A.

\section{Acknowledgments}

This study was supported by the Institut National de la Santé et de la Recherche Médicale (INSERM), Centre National de la Recherche Scientifique (CNRS), Université Pierre et Marie Curie (UPMC) Paris 6, and by a grant from Pfizer (Aspire Hemophilia research award 2014 WI185623). PF-06250112 was a gift from Pfizer according to a 'Compound Transfer Program'-grant. The monoclonal mouse FVIII heavy chain-specific IgG mAb6 was a kind gift from Prof Jean-Marie Saint-Remy (KUL, Leuven, Belgium). JR and MI were recipients of fellowships from Ministère de l'Enseignement Supérieur et de la Recherche. We would like to acknowledge Carole Lasne at the Centre $d^{\prime}$ Explorations Fonctionnelles (CEF) for technical support and the Centre d'Histologie, d'Imagerie et de Cytométrie (CHIC) (Centre de Recherche des Cordeliers, Paris, France).

\section{References}

1. Ehrenforth S, Kreuz W, Scharrer I, Kornhuber B. Factor VIII inhibitors in haemophiliacs. Lancet. 1992;340(8813):253.

2. Lollar P. Pathogenic antibodies to coagulation factors. Part one: factor VIII and factor IX. J Thromb Haemost. 2004;2(7):10821095.

3. Sakurai Y, Shima M, Tanaka I, Fukuda K, Yoshida K, Yoshioka A. Association of antiidiotypic antibodies with immune tolerance induction for the treatment of hemophilia A with inhibitors. Haematologica. 2004;89(6): 696-703.

4. Gilles JG, Desqueper B, Lenk H, Vermylen J, Saint-Remy JM. Neutralizing antiidiotypic antibodies to factor VIII inhibitors after desensitization in patients with hemophilia
A. J Clin Invest. 1996;97(6):1382-1388.

5. Hausl C, Ahmad RU, Sasgary M, et al. Highdose factor VIII inhibits factor VIII-specific memory B cells in hemophilia A with factor VIII inhibitors. Blood. 2005;106(10):34153422

6. Holstein K, Batorova A, Carvalho M, et al Current view and outcome of ITI therapy - a change over time? Thromb Res. 2016; 14838-14844.

7. Oldenburg J, Austin SK, Kessler CM. ITI choice for the optimal management of inhibitor patients - from a clinical and pharmacoeconomic perspective. Haemophilia. 2014;20 (Suppl) 617-626.

8. Coppola A, Di Minno MND, Santagostino E. Optimizing management of immune tolerance induction in patients with severe haemophilia A and inhibitors: towards evi- dence-based approaches. Br J Haematol. 2010;150(5):515-528.

9. Leissinger C, Josephson CD, Granger S, et al Rituximab for treatment of inhibitors in haemophilia A. A phase II study. Thromb Haemost. 2014;112(3):445-458.

10. Lacroix-Desmazes S, Navarrete A-M, André S, Bayry J, Kaveri SV, Dasgupta S. Dynamics of factor VIII interactions determine its immunologic fate in hemophilia A. Blood. 2008;112(2):240-249.

11. Zerra PE, Cox C, Baldwin WH, et al. Marginal zone B cells are critical to factor VIII inhibitor formation in mice with hemophilia A. Blood. 2017;130(23):2559-2568.

12. Rajewsky K. Clonal selection and learning in the antibody system. Nature. 1996;381 (6585):751-758

13. Kurosaki T, Aiba Y, Kometani K, Moriyama 
S, Takahashi Y. Unique properties of memory B cells of different isotypes. Immunol Rev. 2010;237(1):104-116.

14. Khan WN, Alt FW, Gerstein RM, et al. Defective $B$ cell development and function in Btk-deficient mice. Immunity. 1995;3(3): 283-299.

15. Di Paolo JA, Huang T, Balazs $M$, et al. Specific Btk inhibition suppresses B cell- and myeloid cell-mediated arthritis. Nat Chem Biol. 2011;7(1):41-50.

16. Honigberg LA, Smith AM, Sirisawad M, et al. The Bruton tyrosine kinase inhibitor PCI32765 blocks B-cell activation and is efficacious in models of autoimmune disease and B-cell malignancy. Proc Natl Acad Sci U S A. 2010;107(29):13075-13080

17. Hendriks RW, Yuvaraj S, Kil LP. Targeting Bruton's tyrosine kinase in B cell malignancies. Nat Rev Cancer. 2014;14(4):219-232.

18. Rankin AL, Seth N, Keegan S, et al. Selective inhibition of BTK prevents murine lupus and antibody-mediated glomerulonephritis. J Immunol. 2013;191(9):4540-4550.

19. Benson MJ, Rodriguez V, von Schack D, et al. Modeling the clinical phenotype of BTK inhibition in the mature murine immune system. J Immunol. 2014;193(1):185-197.

20. Dumont JA, Liu T, Low SC, et al. Prolonged activity of a recombinant factor VIII-Fc fusion protein in hemophilia A mice and dogs. Blood. 2012;119(13):3024-3030

21. Delignat S, Dasgupta S, André S, et al. Comparison of the immunogenicity of different therapeutic preparations of human factor VIII in the murine model of hemophilia A. Haematologica. 2007;92(10):1423-1426.

22. Dimitrov JD, Dasgupta S, Navarrete A-M, et al. Induction of heme oxygenase-1 in factor VIII-deficient mice reduces the immune response to therapeutic factor VIII. Blood. 2010;115(13):2682-2685.

23. Hausl C, Ahmad RU, Schwarz HP, et al. Preventing restimulation of memory B cells in hemophilia A: a potential new strategy for the treatment of antibody-dependent immune disorders. Blood. 2004;104(1):115122.

24. Delignat S, Repessé Y, Gilardin L, et al. Predictive immunogenicity of Refacto AF. Haemophilia. 2014;20(4):486-492.

25. Nutt SL, Hodgkin PD, Tarlinton DM, Corcoran LM. The generation of antibody- secreting plasma cells. Nat Rev Immunol. 2015;15(3):160-171

26. Meeks SL, Cox CL, Healey JF, et al. A major determinant of the immunogenicity of factor VIII in a murine model is independent of its procoagulant function. Blood. 2012;120 (12):2512-2520

27. Wroblewska A, van Haren SD, Herczenik E, et al. Modification of an exposed loop in the C1 domain reduces immune responses to factor VIII in hemophilia A mice. Blood. 2012;119(22):5294-5300.

28. Mahévas M, Michel M, Weill J-C, Reynaud C-A. Long-lived plasma cells in autoimmunity: lessons from B-cell depleting therapy. Front Immunol. 2013; 4:494

29. Meslier Y, André S, Dimitrov JD, et al Bortezomib delays the onset of factor VIII inhibitors in experimental hemophilia A, but fails to eliminate established anti-factor VII IgG-producing cells. J Thromb Haemost. 2011:9(4):719-728.

30. Liu CL, Lyle MJ, Shin SC, Miao CH Strategies to target long-lived plasma cells for treating hemophilia A inhibitors. Cell Immunol. 2016;30165-30173.

31. Qian J, Collins M, Sharpe AH, Hoyer LW. Prevention and treatment of factor VIII inhibitors in murine hemophilia A. Blood. 2000;95(4):1324-1329.

32. Herman SEM, Gordon AL, Hertlein E, et al. Bruton tyrosine kinase represents a promising therapeutic target for treatment of chronic lymphocytic leukemia and is effectively targeted by PCI-32765. Blood. 2011;117(23):6287-6296.

33. Navarrete A, Dasgupta S, Delignat S, et al. Splenic marginal zone antigen-presenting cells are critical for the primary allo-immune response to therapeutic factor VIII in hemophilia A. J Thromb Haemost. 2009;7(11): 1816-1823.

34. Lai JD, Cartier D, Hartholt RB, et al. Early cellular interactions and immune transcriptome profiles in human factor VIII-exposed hemophilia A mice. J Thromb Haemost. 2018;16(3):533-545

35. Kraal G, Mebius R. New insights into the cell biology of the marginal zone of the spleen. In: International Review of Cytology. Academic Press; p175-215.

36. Rossi G, Sarkar J, Scandella D. Long-term induction of immune tolerance after block- ade of CD40-CD40L interaction in a mouse model of hemophilia A. Blood. 2001;97(9): 2750-2757.

37. Reipert BM, Sasgary M, Ahmad RU, Auer W, Turecek PL, Schwarz HP. Blockade of CD40/CD40 ligand interactions prevents induction of factor VIII inhibitors in hemophilic mice but does not induce lasting immune tolerance. Thromb Haemost. 2001:86(6):1345-1352

38. Smith CI, Baskin B, Humire-Greiff P, et al. Expression of Bruton's agammaglobulinemia tyrosine kinase gene, BTK, is selectively down-regulated in T lymphocytes and plasma cells. J Immunol. 1994;152(2):557-565.

39. Meslier Y, André S, Teyssandier M, Kaveri SV, Lacroix-Desmazes S. Maternally transferred anti-factor VIII IgG reduce the antifactor VIII humoral immune response in factor VIII-deficient mice. Immunology 2010;131(4):549-555.

40. Hartholt RB, Wroblewska A, Herczenik E, et al. Enhanced uptake of blood coagulation factor VIII containing immune complexes by antigen presenting cells. J Thromb Haemost. 2017;15(2):329-340

41. Jacquemin MG, Desqueper BG, Benhida A et al. Mechanism and kinetics of factor VII inactivation: study with an IgG4 monoclonal antibody derived from a hemophilia A patient with inhibitor. Blood. 1998;92(2): 496-506.

42. Jacquemin M, Benhida A, Peerlinck K, et al A human antibody directed to the factor VIII C1 domain inhibits factor VIII cofactor activity and binding to von Willebrand factor. Blood. 2000;95(1):156-163.

43. Moreau A, Lacroix-Desmazes S, Stieltjes N, et al. Antibodies to the FVIII light chain that neutralize FVIII procoagulant activity are present in plasma of nonresponder patients with severe hemophilia $\mathrm{A}$ and in normal polyclonal human IgG. Blood. 2000;95(11): 3435-3441

44. Macauley MS, Pfrengle F, Rademacher C, et al. Antigenic liposomes displaying CD22 ligands induce antigen-specific B cell apoptosis. J Clin Invest. 2013;123(7):3074-3083.

45. Hay CRM, DiMichele DM, International Immune Tolerance Study. The principal results of the International Immune Tolerance Study: a randomized dose comparison. Blood. 2012;119(6):1335-1344. 